\title{
Effects of Technology on Organizational Culture and Climate and Ethics: Implications for Human Service and
} Professional Outcomes

\author{
Randall E. Basham \\ University of Texas at Arlington, Texas, United States
}

\begin{abstract}
The study of the key empirical literature, the role of the effect of information, and communication technologies on culture and climate in organizations is a relatively recent phenomenon in administration, though there is some historical context from the empirical literature. Climate and its impact on various organizational outcomes have been investigated for less than the past 35 years. Little is available in the literature with respect to the impact of culture and climate on the role of ethics within organizations. This presentation of current studies will review and critically analyze recent quantitative research concerning ethical outcomes and the influence of organizational factors on ethical outcomes with potential relevance human service delivery organizations and to social work practice and related professions.
\end{abstract}

Keywords: technology, ethics, culture, climate, social work, outcomes

\section{Ethics and Organizational Culture and Climate}

Organizational services and outcomes may be substantially affected by technological advances and utilization considerations. Organizational culture and climate and the interface of technology are considered mediating influences on professional ethical outcomes. Agency environments, policy, politics, and leadership may be likely to promote ethical adherence or ethical violation within different forms of organizations or within different dimensions of organizational climate. Information and communication technologies available within organizations may substantially influence these outcomes.

For example, the emergence of information and communication technologies have influenced, information sharing and access, social networking at or away from work. Additionally, document privacy and access, permissions and security, and such issues as emerging or revisionist histories, loss of archived primary documents, "fake news", and others may influence both corporate and individual values and institutional memory. Excessive boundary issues, such as being accessible or on call around the clock, may establish a culture of boundary erosion and diffusion of clear organizational or community norms.

Ethical codes require adoption of professional standards in addition to those covering client, or customer and professional relationships. These other areas of endorsement, which include standards of conduct related to

Randall E. Basham, Ph.D., associate professor, School of Social Work, University of Texas at Arlington, Texas, United States.

Correspondence concerning this article should be addressed to Randall E. Basham, Ph.D. Box 19129, the University of Texas at Arlington, 211 S. Cooper St. Arlington, Texas 76019-0129, United States. 
doing no harm, deception, colleague relationships, supervisory relationships, and negotiation and hiring practices, may be the first casualties of ethical misconduct, or buring of boundaries and rules that may have not been rigorously enforced by the professions, or organizational culture.

Much of the literature on ethics is conceptual rather than empirical. The orientation of such literature is frequently to define ethical misconduct as willful misconduct, moral failing, impairment, or a mitigating circumstance due to the failing of an aspect of a personal support system. However, recently the role of organizational culture and climate on ethical outcomes has emerged through publicized examples and empirical analysis. Yet, only more recently, has awareness of the effects of technology upon the formation and maintenance of organizational practices and norms occurred.

\section{Historical Examples}

Consider the implications of a classic study in obedience to authority figures whereby subjects readily violated their own values and were willing to excessively punish others in response to authoritative directives (Milgram, 1963). Authoritative leadership as a function of such studies has often influenced subject outcomes dramatically. Advances in technological apparatus, at that time, made the negative study outcomes more likely. Then add the possibilities, of taking perceived problematic organizational personnel out of the loop, socially isolating, denying access to work tools or information, delegating through emails, which in number being overwhelming to archive or recall, to potential authoritative practices.

In the past, a similar example occurred over a protracted period of time in the documented Tuskegee study. The study had originally been organized to study the long-term effects of syphilis on a cohort of black males. However, after the discovery of antibiotics, which could cure the infections, the study continued for decades without notification or treatment of the subjects. A physician called public attention to the study. He had worked several years as a member of the research team. Many of the research investigators had, as members of medical and related professions, agreed to do no harm by virtue of prior endorsement of professional membership standards. The design of the study and its development created an organizational climate at odds with previous values and commitments (Kampmeier, 1972). Nonetheless, access to timely information adversely affected the study subjects and contributed to organizational withholding of critical intervention and knowledge.

\section{Defining Organizational Culture and Climate}

Various conceptual thinkers have defined organizational climate differently. For the purpose of this review, climate will be defined simply as the shared perceptions of organizational policies, practices, and procedures, both formal and informal (Schneider, 1990). Organizational culture may be defined as including systems of shared meanings, assumptions, and values (Schein, 1985). Ethics are defined within each of the varying professions and institutions participating in these research efforts, with some degree of commonality based in agreed social morality. Technology may affect organizations across each of the organizational phenomena.

\section{An Historical Empirical Literature on Ethical Culture and Ethical Climate}

A literature review was completed of key and seminal empirical literature, in addition to a selected review of literature on the conceptual development of organizational culture and climate literature since 1980. Several databases were searched including Business Abstracts, Econlit, Healthstar, Proquest, Psychinfo, Medline, Social Sciences Abstracts, and Social Work Abstracts. Keywords searched included "ethics", "colleage ethics", 
"employer ethics", "management ethics", "peer ethics", "professional ethics", "organizational climate", "organizational culture", and "service outcomes". Additionally, references to selected classical cases offered in the introduction were sought. Some empirical work has been directed toward clarifying dimensions of organizations, which contribute to ethical outcomes.

\section{Organizational Dimensions and Ethics}

An historical but empirically based field survey study attempted to differentiate between the potential effects of the two related constructs of ethical culture and ethical climate, on employee attitudes and behaviors (Trevino, Butterfield, \& McCabe, 1998). Issues of convergence and divergence of the two constructs were evaluated through both correlational and factor analysis approaches. The study field survey was mailed to a sample of 1,200 alumni from two colleges from the Northeastern United States. One thousand one hundred and seventy-nine surveys were successfully mailed with a return response rate of 275. Alumni had graduated between five and 30 years prior to the mailing and were engaged in a variety of occupations. About half of the respondents reported working in an environment with a code of ethics and half did not. The Ethical Climate Questionnaire along with additional items designed to tap into ethical culture was included. Control variable measures included job satisfaction, and impression of management, or social desirability in responses. Dependent variables included measures of organizational commitment and observed unethical behavior. Statistical analysis included hierarchical regression analysis to evaluate influences of ethical climate and culture on commitment and behavior. Correlational analysis was conducted to determine if correlation's of measures within constructs were higher on average than those between constructs. Should the within correlation's be on average higher than the between correlation's, then divergence of the two constructs would be suggested.

Results of the correlational analysis suggested that the two constructs are highly associated but, tap into different organizational types with respect to ethics. Results of a regression analysis suggested that ethical climate based dimensions were more strongly associated with observed unethical conduct in non-ethical code organizations. The ethical culture based dimension was more strongly associated with observed unethical conduct in organizations having ethical codes.

\section{Ethical Climate}

Several studies have appeared in the business literature, over time, which empirically examine ethical climate in a variety of contexts. For example, one recent study (Wimbush, Shepard, \& Markham, 1997a) attempted to determine whether ethical climate dimensions identified by earlier researchers (Victor \& Cullen, 1987) could be replicated in the subunits of a multi-unit organization. The earlier research had relied on a theoretical typology of organizational forms of government (Ouchi, 1980) to include markets, bureaucracies, and clans. The earlier work by Victor and Cullen had suggested five ethical climate dimensions. These had been identified as a caring dimension, a law and code dimension, a rules dimension, an instrumental dimension, and an independence dimension. The more recent study by Wimbush, Shepherd, and Markham identified another dimension labeled service, which contributed to ethical climate. However, this study supported only three of the five dimensions proposed by Victor and Cullen to include laws and rules, independence, and instrumental dimensions contributing to ethical climate with the added dimension of service.

This current research effort used the 36 item Ethical Climate Questionnaire which was distributed to 4,800 employees in retail stores, a central office, and offices which handled customer credit had a low response rate (12\% returned from store employees, $25 \%$ from credit centers, and $32 \%$ from central office employees). The 
research used analysis of variance techniques to investigate sub-units and dimensions of climate. Factor analysis was also used to examine item responses. Predictability of ethical climate criterion was met in the law and rules dimension for credit center employees only. When ethical climate was examined for the entire organization without regard for sub-units the service climate was reported as most predominant. However, the low survey response rate may well limit attempts to draw meaningful conclusions from this survey on organizational sub-unit dimensions and ethics.

A second study by the same authors (Wimbush, Shepard, \& Markham, 1997b) attempted to test relationships between the earlier identified organizational dimensions and ethical behavior (Wimbush, Shepard, \& Markham, 1997a) at different levels of analysis. The Ethical Climate Questionnaire and Work Station Questionnaire were mailed to 4,400 employees in 440 retail stores throughout the United States. The Work Station Questionnaire was composed of a series of case vignettes, while the Ethical Climate Questionnaire was a Likert type scale. Both were self-report measures. The response included 643 surveys returned of which 118 were discarded due to employees not disclosing whether they worked in stores or another organizational unit such as the credit office. Relationship between ethical climate and ethical behavior was evaluated at individual and district levels of analysis. The study used Within and Between Analysis (WABA) and found partial support for a relationship between ethical dimensions and behavior. There was a lack of findings at the district level suggesting that ethical climate may be a greater consideration within the unit or workgroup than within the larger organization.

\section{Ethical Climate and Person-Organization Fit}

An interesting recent study proposed to investigate the possibility of a relationship between the ethical climate of the organization and the development of person-organization fit (Sims \& Keon, 1997). The investigators surveyed 98 working students from two different universities, which included 46 MBA students and 52 undergraduate students. Students completed an Intention to Turnover Scale, Minnesota Satisfaction Scale, and during a second session completed the Preferred Work Climate Questionnaire, and finally completed a Defining Issues Test in a third session. Correlation's of climate and moral development were calculated along the five dimensions as proposed by Victor and Cullen in 1987, as well as preferred and present ethical climate, and absolute differences and work attitudes, and difference scores and work attitudes. Results supported that a match between individual preferences and present position was more satisfying. Subjects expressing a match between present and preferred ethical climate were less likely to seek to leave their positions. However, the study provided only partial support for the concept that a match between individuals and organizations with similar ethics provided the most satisfying environments. The study has implications both for recruitment and retention of employees.

\section{Ethical Climate and Job Satisfaction}

A separate investigation (Deshpande, 1996) sought to examine the impact of ethical climate as proposed by the dimensions identified in earlier studies on specified facets of job satisfaction. Ethical climate types were labeled as professionalism, caring, rules, instrumental, efficiency, and independence. Facets of job satisfaction were labeled as pay, promotions, co-workers, supervisors, and the work itself. A national sample of 252 middle level managers in a large non-profit charitable organization was surveyed with 825 responding. The dimensions of ethical climate were reported in prevalence as listed above on a 4-point Likert scale. Respondents were most satisfied with the facet of work and least satisfied with pay. Regression analysis indicated that ethical climate 
influenced satisfaction with pay, whereas, a professional climate influenced overall job satisfaction, and satisfaction with promotions, supervisors, and work. Respondents who believed that the organization had a caring climate were more satisfied with supervisors. An instrumental climate had a strong negative effect on all facets but pay satisfaction. Efficiency and independence dimensions did not effect any facets. This study suggests that organizations may be able to influence all facets of job satisfaction but pay satisfaction, by changing dimensions of ethical climate.

A subsequent study that included the previous researcher examined the impact of ethical climate types on various facets of job satisfaction of nurses employed at a large non-private private hospital (Joseph \& Deshpande, 1997). Ethical climate types and facets of work were examined as in the previous study. The staff of 226 nurses was surveyed with a return rate of $50 \%$ of the surveys. Regression analysis of the returned responses indicated that professional, instrumental and independence climate types had no impact on any facet of job satisfaction. A caring climate was found to significantly influence overall job satisfaction and satisfaction with pay and supervisors. A rules climate also had a significantly positive impact on overall job satisfaction. However, an efficiency climate had a significant negative influence on satisfaction with supervisors.

\section{The Enduring Nature of Early Exposure to Ethical Codes}

A different approach was taken in a separate study to determine the enduring nature of academic and organizational ethical code influences on longer-term ethical behaviors. This recent study specifically examined the influence of collegiate honor codes and corporate codes of conduct on ethics related behavior in the workplace (McCabe, Trevino, \& Butterfield, 1996). Codes of conduct were defined as a community's attempt to communicate its expectations and standards of ethical behavior.

Subjects were surveyed from two colleges with each alumni group being mailed 582 surveys. All recipients had graduated between 1962 and 1989. One college had a history of an honor code system and the other did not. Survey completion and return was voluntary. The "code" college returned $27 \%$ of completed surveys with the "no-code" college returning $28 \%$ of the surveys. There were no significant differences in response rate due to gender or year of graduation. The average age of subjects was 39.7 years with subjects averaging 8.4 years in their current organization and an average of 5.3 years in their current position.

Results revealed no significant differences between the "code" and "no-code" college alumni with respect to self-reported unethical behavior. However, results did reveal significant differences in self-reported unethical behavior between individuals working in organizations with a "code" of ethics and those working in organizations with "no-code". Both the perceived embeddedness of the organizations code ethics and strength of code implementation had a significant inverse relationship on self-reported behavior. A statistical moderated hierarchical regression analysis, which controlled for social desirability bias, demonstrated that strength of code implementation had a significant main effect on self-reported behavior.

\section{Ethics, Individual and Situational Factors}

In a recent experimental examination of the effects of individual and situational factors on unethical behavioral intentions in the work place, two groups of workers, 138 upper level undergraduate students, and 154 MBA evening class participants with an average of five years work experience were examined (Jones \& Kavenaugh, 1996). The study examined three situational variables: (1) quality of the work experience; (2) peer influencesl; and (3) managerial influences, as well as three individual variables, (4) locus of control; (5) machiavellianism (a scale measured construct); and (6) gender. 
Participants completed a questionnaire, which measured locus of control, Machiavellianism, and social desirability. All subjects read ethically ambiguous scenarios and completed two questionnaires (checking responses and experimental manipulations) and also completed a demographics form. Afterward, subjects were debriefed on the purpose and procedures of the study.

Results of one experiment revealed main effects for quality of work experience, Machiavellianism, and managerial influences and interaction effects for both peer influences and managerial influences on individual ethical responses. Results of a different experiment revealed main effects for all three situational variables (quality of work experience, peer influences, and managerial influences) and Machiavellianism. Neither experiment supported gender differences in ethical responses.

\section{Ethical Climate and Unethical Bargaining Tactics}

An earlier (April 1998) study empirically evaluated the negotiation and bargaining ethics of 320 MBA students enrolled in a negotiation class (Lewicki \& Robinson, 1998). The data were collected in multiple iterations over the course of a two-year period at Ohio State University. Later, the study was repeated with 736 first year MBA students at Harvard. Participants represented various ethnic, gender, nationality, age, and professional backgrounds. Managers from various backgrounds and disciplines are thought to spend a substantial portion of their time in negotiation. Students were asked to evaluate a number of marginally acceptable negotiation practices early in their course before having an opportunity to practice them. These were classified as follows:

- Misrepresentation of information, to include justification of position, retribution against an opponent, preserving confidentiality or face saving.

- Traditional competitive bargaining, to include hiding a bottom line, making inflated opening demands, securing information about your opponent, undermining an opponent's confidence, and stalling or delaying negotiation process.

- Bluffing, to include false threats, false promises, and cutting off an opponent's options to pursue options elsewhere.

- Manipulation of an opponent's network, to include undermining the negotiators support system or constituency by talking to a boss or network, encouraging erosion of support through defections, and threatening to embarrass an opponent.

- Inappropriate information gathering, to include, paying informants for information about an opponent, seduction or recruiting an opponent's constituents to your side, and gaining information in exchange for gifts or favors.

Of 18 possible negotiation tactics included in these definitions, four had been considered appropriate, two marginal, and 12 as inappropriate and unlikely to use. However, some results of the study indicated that the Harvard sample was more likely to use a greater number of the inappropriate tactics than the Ohio State University sample. Discussion focused on the need for further research to determine if the Harvard students were simply more aggressive or differently socialized in an environment with alternative expectations regarding acceptable negotiating practices. Thus the question of whether unethical practices are a function of personality traits, environment, or some combination of both may require further empirical study.

\section{Those Who Report Organizational Violations}

A qualitative and quantitative analysis of 33 cases of internal and external whistleblowers who were wrongfully fired for reporting wrongdoing were investigated in one recent study (Dworkin \& Baucus, 1998). 
Research focused on cases litigated in the legal literature and used a multiple case study design with chi square and means comparison techniques to test hypotheses and match patterns. There was some support for hypotheses that:

- younger employees reported externally while senior employees reported internally;

- external reporters held greater evidence and witnesses;

- internal whistleblowers were less effective;

- physical wrongdoing occurs to external whistleblowers;

- psychological harm and economic harm occurs to internal whistleblowers;

- external whistleblowers face delayed firing;

- internal whistleblowers face more immediate firing.

Limitations of the study included legal cases only, missing data (especially demographic), and only whistleblowers that suffered retaliation were available for study.

\section{Ethical Climate and Service Outcomes}

A recent American Psychological Association (APA) survey on Managed Care was mailed to 1,000 members of the APA's Division 42 in 1996 (Murphy, Bernardo, \& Shoemaker, 1998). The survey yielded a $44 \%$ return rate. The sample had been randomly selected. Respondents were reported to be representative of experienced and well established doctoral-level practitioners. All such practitioners would have endorsed a professional code of ethics in licensure or through joining their professional association. Approximately $84 \%$ were members of Health Maintainance Organizations (HMO) and Preferred Provider Organizations (PPO). The organizational structure of $52 \%$ of respondents' practices had been changed in response to managed care. Survey respondents had disclosed that managed care had produced ethical dilemmas for them. Encountering persistent difficulties with managed care was reported by $25 \%$ of respondents, while $45 \%$ related more concerns than would be consistent with general practice. In situations where a patient's coverage was terminated before the patient had made substantial treatment gains, respondents endorsed these alternatives in the following percentages:

advocating for more benefits (90\%), followed by continuing treatment with the patient paying out of pocket (88\%), reducing the fee in order for the patient to self pay (86\%), treating the patient pro-bono (69\%), referring the patient out $(44 \%)$, terminating treatment $(27 \%)$, and altering the diagnosis so treatment would be covered (9\%).

Most respondents also indicated that managed care had led to inappropriate providers of treatment, rejection of patients with certain diagnoses, and use of medication in lieu of therapy. With respect to patient confidentiality and managed care, the surveyed psychologists responded with $75 \%$ agreement that patient confidentiality is compromised with managed care, and 53\% had little confidence that information would not be disclosed. Moreover, $63 \%$ of the psychologists responding related feeling that there was a high potential that information forwarded to managed care companies could be used to harm the patient.

\section{Discussion and Research Review Implications}

Solutions proposed or implied in current research point to determining the organizational form with the best fit for ethical outcomes. Identifying the dimensions of climate associated with ethical outcomes is importance as well. The selection of employees for specified positions who are matched with ethical climate needed for the position is a consideration. Additionally, determination of facets of the job that are best related 
to ethical outcomes and job satisfaction are suggested. Some further studies also recommend avoidance of the conclusion that past honor code experiences will predict ethical behavior. Organizations that promote embeddedness of codes of ethics and strongly implement codes may reduce unethical behavior, however. Other suggestions include reducing unethical managerial influences, improving the quality of work experience, and screening out perspective employees with high Machiavellian traits, as directions to improve ethical outcomes.

Further research suggestions included determining if environmental socialization and organizational expectations influence unethical negotiation tactics or other unethical behaviors. Researches on development of methods to report unethical behavior that promote and reward disclosure are needed. Additional research is also needed to discover how outside organizations, such as managed care organizations and financial incentives affect organizational culture and climate, as well as, ethical adherence and service outcomes.

The most interesting finding of this review, however, is the absence or limited number of empirically based studies on the effects of organizational culture and climate on ethics in the many bodies of professional literature. Certainly, there are numerous codes of ethics and legal articles promoting both codes and including elegant case examples. Many more devote themselves to a theoretical examination of a specific controversial issue within a particular code. Yet, others are preoccupied to some extent with comparisons of inter-professional ethics. However, little is empirically examined about the multiple organizational, social, economic, and political environments, which may impact ethics and thus service outcomes.

Several of the reviewed studies relied on non-experimental survey methods with poor response rates and missing data. There were no specified control groups in most studies. Attempts to control for interactions effects or adequate design to control for the effects of covariates were limited. Interventions with pretest and posttest examinations to rigorously test the impact of culture and climate were also limited. Most designs used self-report measures only. None of the studies attempted to define models to explain the mechanism and sources of variance for strength of relationships hypothesized. Some hypothesis tested appeared to have a limited relationship to ethical concerns. In the case of the study related to early exposure to ethical codes, little was done to explain intervening factors over the years since graduation from school of subjects, which might alternately explain ethical differences. Most studies were related to business ethics where the professionals examined were not necessarily required to endorse a standard code of ethics. Future studies on the effect of culture and climate on ethics and service outcomes should strive to resolve design limitations and relate more specifically to those occupations heavily defined and regulated by ethical codes and include the effect of organizational technology on the development of culture and climate.

\section{Implications for Research and Human Services Organizations and Professions}

Much of professional life and services occur in organizational contexts for organizations that include human service delivery and social workers, or related professions. Little if anything is known with respect to what cultural and climate influences contribute to the co-opting of professional ethics and as these relate to emerging and currently utilized technologies. Such concerns have traditionally been examined conceptually and without empirical research, from the perspective of individual failures, support system failures, or moral failures rather than systemic forces and the iatrogenic effects of technology. Current research in other disciplines should be utilized to consider methods of constructing investigations of organizational culture and climate effects on social work ethical outcomes. Empirical techniques of ascribing causality and constructing predictive models through rigorous testing and replication of results is needed in service delivery and 
professional literature as related to human services and the profession of social work and similar fields of practice.

\section{Conclusion}

This manuscript contributes to the limited available research and review of organizational culture and climate and as these managerial constructs are recently effected by emerging technologies. Professional ethics, especially where data confidentiality and personal records of various types are concerned may be substantially compromised. Technology itself within organizations is rapidly changing the norms of organizational rules and policy. Perceptions of the affected employees or managerial officers of what are permissible or not permissible to know of the affairs of others are being abridged. Confidences broken or reputational damage may not be due to the conduct of the organizational member, but simply an artifact of intrusive technologies beyond the needed scope for operations for many organizations. There may actually be few moral or personal failures but only the perception of such as a byproduct or artifact of overly robust organizational technology and human misuse of information or misinterpretation.

\section{References}

Deshpande, S. P. (1996). The impact of ethical climate on facets of job satisfaction: An empirical investigation. Journal of Business Ethics, 15, 655-660.

Dworkin, T. M., \& Baucus, M. S. (1998). Internal vs. external whistleblowers: A comparison of whistleblowering processes. Journal of Business Ethics, 17, 1281-1298.

Jones, G. E., \& Kavenaugh, M. (1996). An experimental examination of the effects of individual and situational factors on unethical behavioral intentions in the workplace. Journal of Business Ethics, 15, 511-523.

Joseph, J., \& Deshpande, S. P. (1997). The impact of ethical climate on job satisfaction of nurses. Health Care Management Review, 22(1), 76-81.

Kampmeier, R. H. (1972). The Tuskegee study of untreated Syphillis. Southern Medical Journal, 65, 1247-1251.

Lewicki, R. J., \& Robinson, R. J. (1998). Ethical and unethical bargaining tactics: An empirical study. Journal of Business Ethics, $17,665-682$.

McCabe, D. L., Trevino, L. K., \& Butterfield, K. D. (1996). The influence of collegiate and corporate codes of conduct on ethics-related behavior in the workplace. Business Ethics Quarterly, 6(4), 461-476.

Milgram, S. (1963). Behavioral study of obedience. Journal of Abnormal Social Psychology, 67, 371-378.

Murphy, M. J., Bernardo, C. R. D., \& Shoemaker, W. E. (1998). Impact of managed care on independent practice and professional ethics: A survey of independent practitioners. Professional Psychology Research and Practice, 29(1), 43-51.

Ouchi, W. G. (1980). Markets, bureaucracies, and clans. Administrative Science Quarterly, 25, 129-141.

Schein, E. (1985). Organizational culture and leadership: A dynamic view. San Francisco: Jossey-Bass.

Schneider, B. (Ed.). (1990). Organizational climate and culture. San Francisco: Jossey-Bass, Inc. Publishers.

Sims, R. L., \& Keon, T. L. (1997). Ethical work climate as a factor in the development of person-organization fit. Journal of Business Ethics, 16, 1096-1105.

Trevino, L. K., Butterfield, K. D., \& McCabe, D. L. (1998). The ethical context in organizations: Influences on employee attitudes and behaviors. Business Ethics Quarterly, 8(3), 447-476.

Victor, B., \& Cullen, J. B. (1987). A theory and measure of ethical climate in organizations. Research in Corporate Social Performance and Policy, 9, 51-71.

Wimbush, J. C., Shepard, J. M., \& Markham, S. E. (1997a). An empirical examination of the multi-dimensionality of ethical climate in organizations. Journal of Business Ethics, 16, 67-77.

Wimbush, J. C., Shepard, J. M., \& Markham, S. E. (1997b). An empirical examination of the relationship between ethical climate and ethical behavior from multiple levels of analysis. Journal of Business Ethics, 16, 1705-1716. 